Sharif University of Technology
Scientia Iranica
Transactions E: Industrial Engineering
hCIENTIA

\title{
Fuzzy mathematical models for maximizing satisfaction of contractors and clients by considering flexible start date of the project
}

\author{
F. Khazaelia , H. Arman ${ }^{\mathrm{b}, *}$, M. Zare ${ }^{\mathrm{a}}$, and A. Hadi-Vencheh ${ }^{\mathrm{c}}$ \\ a. Department of Civil Engineering, Najafabad Branch, Islamic Azad University, Najafabad, Iran. \\ b. Department of Management, Najafabad Branch, Islamic Azad University, Najafabad, Iran. \\ c. Department of Mathematics, Isfahan (Khorasgan) Branch, Islamic Azad University, Isfahan, P.O. Box 81595-158, Iran.
}

Received 15 October 2019; received in revised form 23 April 2020; accepted 3 August 2020

\author{
KEYWORDS \\ Budget allocation; \\ Satisfaction; \\ Fuzzy linear \\ programming; \\ Project management; \\ Resource-Constrained \\ Multi-Project \\ Scheduling Problem \\ (RCMPSP).
}

\begin{abstract}
Resource-Constrained Multi-Project Scheduling Problem (RCMPSP) is considered a significant topic in project management studies and many types of research have been carried out in this field in which numerous approaches have been proposed so far. However, in most of these approaches, the viewpoints of clients and contractors, i.e., two important stakeholders of the project, are not directly considered. The current research attempts to introduce a new approach, namely RCMPSP, to schedule the project portfolio and allocate the budget as a limited resource simultaneously. In doing so, first, clients and contractors' budget satisfaction is defined. Then, a number of budget allocation models have been proposed to maximize the satisfaction of clients and contractors. These models consider such constraints as minimum cost required for each project, maximum budget for each period, and flexibility of the start date of each project. To illustrate the viability of the proposed models, a real case of the project portfolio is considered.
\end{abstract}

(C) 2022 Sharif University of Technology. All rights reserved.

\section{Introduction}

The constrained resources in project management are considered an essential issue. One of the significant resources is the budget. In some projects, clients' fund may radically change over time due to uncertainty in the economy [1]. On the other hand, contractors rarely rely on their savings in projects; thus, clients' proper financing is the first concern of contractors because constraints of the budget allocated to a project affect their indirect costs [2]. Therefore, it can be

\footnotetext{
*. Corresponding author.

E-mail addresses: farhad.khazaeli@gmail.com (F. Khazaeli); hosein.arman@yahoo.com (H. Arman); zare_mr

@yahoo.com (M. Zare); abdh12345@yahoo.com (A. Hadi-Vencheh)
}

doi: $10.24200 /$ sci. 2020.54657 .3850 concluded that money is a vital project resource and its distribution method is one of the essential factors; besides, it is of high importance to choose suitable techniques for project portfolio programming [3].

Resource-Constrained Multi-Project Scheduling Problem (RCMPSP) is a well-known concept for project portfolio programming to ensure that all projects have balanced access to resources in proper timing and this concept has been derived from Resource-Constrained Project Scheduling Problem (RCPSP) models. There are currently two main ways to solve RCMPSP problems. First, all projects are assumed to be a single major project and they are solved using RCPSP methods. Despite the first approach, in the second one, all projects are considered independent with their exclusive critical path; the methods are employed to specify the start and end dates of each project according to the resource constraints [4] and projects 
are not considered to be holding any precedence over one another. Therefore, projects can be initiated in the mid-term of another project, which is in direct contrast to the first approach. The second approach has been studied in many pieces of researches given that it is more realistic and holds less regard for the past researches which, ideally, provide much room for improvement [5].

In order to solve RCMPSP using the independent projects approach (second approach), some researchers have proposed a dual-level approach. In this fashion, project managers make low-level decisions independently to schedule activities, while senior managers make high-level decisions using a set of resources (total resources) for allocation [6]. In this case, project portfolio managers focus on the scheduling of all projects and specify the number of resources for each project at different intervals while the portfolio manager monitors only its implementation.

Regardless of what approaches are used, RCMPSPs are more complicated to solve by ordinary mathematical methods. Hence, several heuristic methods have been proposed in different studies. Most of the heuristic methods used in RCMPSP belong to the Priority Rule (PR) methods, and numerous studies including Gonçalves et al. [7] and Ju and Chen [8] have been conducted in this regard. PRs represent managers' tendencies for project scheduling which can be used separately or concurrently [9]. Project managers need to conduct fast calculations [10]. Therefore, PRs are the tools that help them achieve satisfaction.

The RCMPSP solution methods are subject to some significant shortcomings. In some existing approaches, there is no difference between the independent projects and project portfolio which causes disagreements between the project and portfolio managers. There is also a remarkable difference between research and practical stream in case of constrained resources [10]. On the other hand, due to the dynamic environment of the project in the real world, project scheduling may be restricted to notable uncertainty; for example, activities may be done within a shorter or longer time duration and resources are temporarily unavailable [4]. Therefore, the practical schedule may not align with the models' output.

Another drawback of previous RCMPSP methods is that they do not focus on stakeholders' viewpoints. Allocation of resources, especially financial resources, has a considerable impact on the performance of project stakeholders. It is a fact that a project manager always competes with other project managers for more resources; thus, the initial distribution of resources is based on the competition of project managers. It can result in dissatisfaction [11]. On the other hand, the client must respect contractors' capacities. Project managers and contractors make their decisions inde- pendently and autonomously to minimize their executive costs [12]. However, the benefits of collaboration will ultimately lead to greater satisfaction for them [13]. These facts show that considering the project managers and contractors' viewpoints in budget allocations is extremely important. This issue must be addressed by considering several compromises to reach an acceptable optimal point [14].

One of the best ways to involve the stakeholder's viewpoints in decision making is to use the concept of satisfaction. However, the main question is how satisfaction with budget allocation can be calculated. To this end, Dubois and Fortemps [15] introduced the definition of constraint satisfaction in the resource allocation field so that each resource would have a capacity with lower and upper boundaries as constraints. The allocation will be satisfied if the upper boundary is completely allocated and will not be satisfied if the lower boundary is not reached. Thus, if the client's and contractors' viewpoints about the budget are converted into the interval form including minimum-maximum budget expectation using Dubois and Fortemps' approach, it is possible to calculate the value of satisfaction for budget allocation according to the client's and contractors' viewpoints.

In this research, a new approach is proposed to solve RCMPSP in which satisfaction is considered as the main objective. Thus, three distinct goals are emphasized in this approach: 1) maximizing the client's satisfaction; 2) maximizing the contractors' satisfaction; 3) maximizing the client's and contractors' satisfaction simultaneously. Therefore, the proposed approach is classified into three categories and optimization models are developed for each category. These models are, in fact, a developing form of Dubois and Fortemps [15] satisfaction concept and Zimmermann's approach [16] which maximize the satisfaction with the budget allocation. The models distribute the budget as a cumulative payment with flexibility at the start date of the project versus starting all projects in the first period of portfolio.

This research paper is organized in six sections. The second section consists of literature review. The methodology can be found in the third section. Section 4 presents portfolio evaluation for real case projects. Section 5 includes discussion of the results and the last section contains the conclusion.

\section{Literature review}

Scheduling multi-projects with limited resources is a significant challenge for most of project-based companies. The managers should share common resources with a number of projects in order to achieve the goals defined by firm's strategies. Therefore, solving RCMPSP is a substantial concern of managers. 
Pritsker et al. [17] made the first attempts to solve such problems. They presented a zero-one model and claimed that their model could solve many real-world problems regarding scheduling in limited resources, solving the job shop problems, etc. Three limitations of "decreased time of all projects, decreased the project portfolio makespan, and decreased penalties" were considered in their issue.

Basically, RCMPSPs are too complicated and cannot be solved by traditional mathematical methods [18]. Accordingly, numerous studies have suggested using heuristic and meta-heuristic approaches. For example, Gonçalves et al. [7] and Tseng [19] utilized genetic algorithm to solve RCMPS problems. The results obtained from their study of different projects represented the acceptable performance of the genetic algorithm. Majazi Dalfard and Ranjbar [20] used a genetic algorithm to solve scheduling problems and compared the results with the traditional method. Can and Ulusoy [21] developed a two-step method to allocate the budget. In their method, all projects were initially changed into macro activities and solved using Genetic Algorithm (GA) with maximum Net Present Value (NPV) limit. The shortest execution makespan was determined based on the start time and the resources specified for each project.

In this stream, most of researchers have emphasized using PRs as an adequate tool to enhance their heuristic and meta-heuristic methods. Gonçalves et al. [7] stressed the development of heuristic methods based on PRs. Moreover, Chakrabortty et al. [22] stated that doing activities in proper time (based on resource allocation) would have a sustainable effect on project completion time. Therefore, it is essential that a suitable PR be selected. Kurtulus and Narula [23] introduced PRs for project portfolio scheduling and compared their performance with other PRs. According to their results, when a problem is small, the rules which are based on resource usage are suitable and when the problem is big, techniques based on slack reduction are appropriate.

However, there are significant discrepancies between the results of the research studies. For example, using 6 heuristic RCPS problem-solving methods, Russell [24] demonstrated that project time reduction methods would not necessarily lead to an increase in NPV. In contrast, Chiu and Tsai [25] examined a heuristic approach and concluded that any PR minimizing project delays could result in increased NPV. Therefore, it is helpful to use PR to minimize project runtime. Nevertheless, Herroelen [26] pointed out that management should focus on sustainability rather than reduction of project portfolio time in order to create a stable scheduling program with a desirable duration to prevent small disruptions throughout the program.

Despite all the efforts made to study the PRs, the important question is: 'which PR is appropriate'? In order to answer this question, Browning and Yassine [5] reviewed various $\mathrm{PRs}$ and compared their performance. They introduced some PRs and emphasized that one PR could not be considered superior or inferior. Also, Vázquez et al. [27] studied many PRs and concluded that it would be difficult to categorize and identify all PRs for all working conditions. Furthermore, Wang et al. [4] reviewed the performance of PRs in a contingent state. According to the related pieces in the literature, 20 PRs can be employed to solve RCMPS problems. Their results demonstrated that the performance of PRs depended on the given constraints and they had a significant difference. They concluded that it would be difficult to claim that one PR is suitable for all modes.

On the other hand, regardless of what method or PR has been used, two general approaches are employed to solve RCMPS problems: (1) single-project approach which converts multiple projects into a mega project using dummy tasks and precedence arrows; and (2) multi-project approach that keeps up projects with their exclusive critical path and attempts to allocate them common resources [28]. Nabipoor Afruzi et al. [29] and Zhang et al. [30] employed the first approach to allocate multi-project resources. However, Kurtulus and Davis [31] presented a plan to examine the performance of a single project approach versus that of multiple projects. Their research demonstrated that the multi-project approach outperformed the time when several projects were converted into a virtual single project. Also, Lova and Tormos [32] concluded that a parallel scheduling generation scheme along with a multi-project approach could lead to more appropriate results in allocating limited resources compared to the conversion of several projects into a virtual single project.

In conclusion, a review of the literature shows that although a wide range of approaches have been proposed, based on our studies, mostly the objective of methods has not concentrated on the viewpoints, experiences, and satisfaction of project stakeholders such as project managers and contractors. Indeed, the methods attempt to achieve objectives like shortening the makespan, reducing penalties, reducing resource consumption, or increasing some factors like NPV while such goals can only be realized with the participation of project executive agents. Therefore, planning should be accompanied by their satisfaction which has not been considered in previous researches. Thus, incorporation of the concept of satisfaction into RCMPSP can be examined as a significant point in the development of past methods.

\section{Methodology}

The fuzzy mathematical models presented in this 
study are obtained by developing Zimmermann's approach [16] and are classified into three categories. The first category contains those optimization models whose purpose is to allocate the budget to the projects to maximize client satisfaction. The aim of the models proposed in the second category is to maximize the contractors' satisfaction with the budget allocated to the projects in successive periods. Finally, the third category includes models that allocate the budget with the aim of maximizing the satisfaction of the client and the contractors, simultaneously. These models were established based on the following assumptions:

1. In the models in which the projects are allowed to start by delay, the cost required for the same phases of each project may vary in different periods;

2. The projects must be completed in successive and non-stop periods. In other words, after allocating the first part of the cost to a project, jumping over the next period without allocating any part of the rest cost needed to complete the project is not allowed.

In the following, six models are presented and are described in three different categories.

\subsection{Budget allocation with the aim of maximizing the client satisfaction}

The budget that must be allocated to the projects requires a specific amount of budget in each period. However, optimal budget allocation from the client's point of view may involve a certain amount for each period such that overpayment reduces the client's satisfaction. Figure 1 shows the client's satisfaction of the total budget paid in the period $j$, where $x_{i j}$ is the budget allocated to the project $i$ in the period $j$ $(i=1, \ldots, n ; j=1, \ldots t), n$ the number of projects, $t$ the number of periods, $\sum_{i=1}^{n} x_{i j}$ the total budget paid in the period $j, B_{j}^{L}$ and $B_{j}^{U}$ are the highest and lowest amounts of satisfying and unsatisfying budgets, respectively, which can be paid in the period $j$ from the client's point of view, $\tilde{A}$ is the fuzzy set of client satisfaction with the budget paid in different periods,

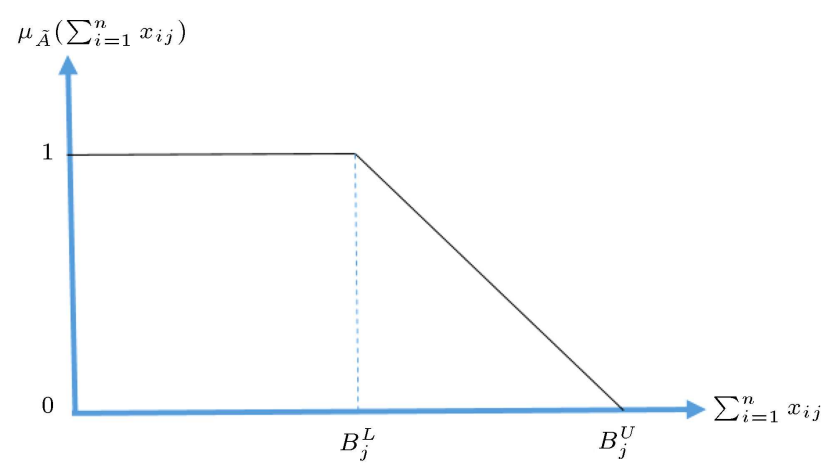

Figure 1. Membership function of the client's satisfaction with the budget paid in the period $j$. and $\mu_{\tilde{A}}\left(\sum_{i=1}^{n} x_{i j}\right)$ is the degree of client satisfaction with the budget paid in the period $j$. If the budget paid in the period $j\left(\sum_{i=1}^{n} x_{i j}\right)$ exceeds $B_{j}^{L}$, the client's satisfaction decreases gradually such that the budget payment equal to $B_{j}^{U}$ is not satisfying for the client.

The start dates of projects can be either unchangeable or flexible. Model I is proposed for conditions when the start dates of projects are fixed and unchangeable. However, if the start dates are flexible, we can use Model A.I given in Appendix A. These models, both, were proposed based on the cumulative budget assumption. In other words, it is assumed that the clients will be satisfied with the budget allocated to each period and previous periods cumulatively.

\section{Model I}

$\max \lambda$,

s.t.:

$$
\begin{aligned}
& \lambda \leq \frac{A B_{j}^{u}-\sum_{i=1}^{n} \sum_{L=1}^{j} x_{i L}}{A B_{j}^{U}-A B_{j}^{L}} \quad \forall_{j}, \\
& \sum_{j=1}^{t} x_{i j}=C_{i} \quad \forall_{i}, \\
& x_{i j} \geq C_{i j} \quad \forall_{i, j},
\end{aligned}
$$

where:

$\lambda \quad$ The client's fixed satisfaction

$x_{i j} \quad$ The budget paid for the project $i$ in the period $j(i=1-n ; j=1-t)$

$A B_{j}^{L} \quad$ The satisfactory cumulative budget from the client's point of view for allocating up to the end of period $j$

$A B_{j}^{U} \quad$ The unsatisfactory cumulative budget from the client's point of view for allocating up to the end of the period $j$

$C_{i} \quad$ Total cost of the project $i$

$C_{i j} \quad$ The minimum cost required for the project $i$ in the period $j$

$n_{i} \quad$ The number of successive periods required to complete the project $i$

Models I and A.I aim to maximize the client's satisfaction which cannot exceed the client's satisfaction specific to each period. It is guaranteed by Objective Functions (1) and (A.1) and Constraints (2) and (A.2) in these models. Moreover, the total budget paid to the project $i$ in all periods should be equal to the total cost of the project guaranteed by Constraints (3) and (A.3) in these models. Also, the minimum budget required for projects in each period must be provided. 
It is guaranteed by Constraints (4) and (A.4) in these models. Model I is used when the start date of each project is fixed and unchangeable. However, in Models A.I, the start date of the projects may vary so that their optimal start date is calculated after solving the given models. Therefore, the binary variable $y_{i}^{k}$ is used which indicates that the project $i$ starts in the period $k$ or does not start. However, the project $i$ has only one start period, which is guaranteed by Constraint (A.5).

\subsection{Budget allocation with the aim of maximizing the contractor satisfaction}

Contractor $i$ requires a determined budget in period $j$ to progress its project. If the allocated budget is lower than the required budget, its satisfaction is reduced. Figure 2 represents the satisfying budget for the contractor $i$ in the period $j$, where $x_{i j}$ is the budget allocated to the project $i$ in the period $j(i=1-n$, $j=1-t) . U_{i j}$ is the minimum budget for the project $i$ in the period $j$ that completely satisfies the contractor $i$. $\quad L_{i j}$ is the maximum budget for the project $i$ in the period $j$ which is completely unsatisfying for the contractor $i$. $\tilde{B}$ is the fuzzy set of the satisfaction of the contractor $i$ and $\mu_{\tilde{B}}\left(x_{i j}\right)$ is the satisfaction degree of the contractor $i$ depending on the allocated budget in the period $j$.

$U_{i j}$ is the minimum value for $x_{i j}$ with a membership degree of 1 in the fuzzy set $\tilde{B}$. If the budget allocated to the project $i$ in the period $j\left(x_{i j}\right)$ is less than $U_{i j}$, the satisfaction of the contractor $i$ decreases. $L_{i j}$ is the maximum value for $x_{i j}$ with the membership degree of zero in the fuzzy set $\tilde{B}$ which has no satisfaction for the contractor $i$ in the period $j$.

Similar to Section 3.1, the start dates of projects can be unchangeable or flexible. Model II has been presented for certain situations where the start dates of projects are fixed and unchangeable. However, if the start dates are flexible, we can use Model B.I in Appendix B. These models, both, were proposed based on the cumulative budget assumption. In other words, it was assumed that the contractors would be satisfied

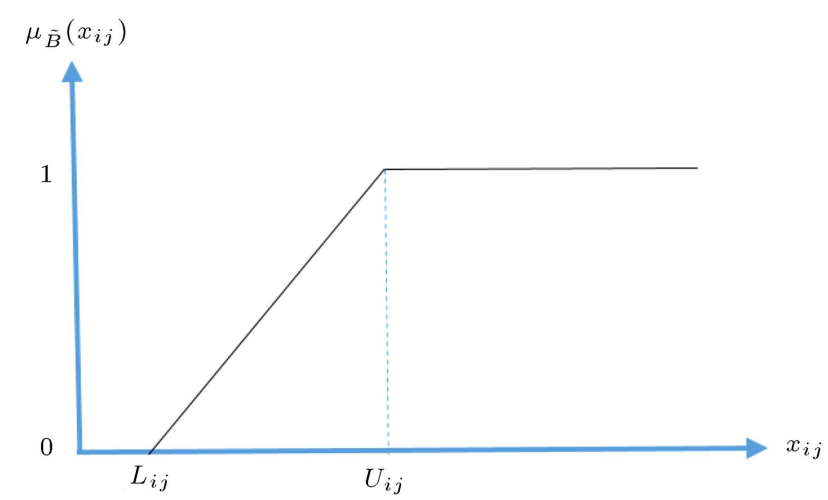

Figure 2. Membership function of the satisfaction of contractor $i$ in the period $j$. with the budget allocated in each period and previous periods cumulatively.

\section{Model II}

$\max \lambda$,

s.t.:

$$
\begin{aligned}
& \lambda \leq \frac{\sum_{h=1}^{j} x_{i h}-A C_{i j}^{L}}{A C_{i j}^{U}-A C_{i j}^{L}} \quad \forall_{i, j}, \\
& \sum_{i=1}^{n} x_{i j} \leq B_{j} \quad \forall_{j}, \\
& \sum_{j=1}^{t} x_{i j}=C_{i} \quad \forall_{i}, \\
& x_{i j} \geq 0 \quad \forall i,
\end{aligned}
$$

where:

$\lambda$ The contractors' final satisfaction

$B_{j} \quad$ The total budget assigned to the period $j$

$A C_{i j}^{L} \quad$ The unsatisfying cumulative cost from the contractor's point of view for the project $i$ up to the end of the period $j$

$A C_{i j}^{U} \quad$ The satisfying cumulative cost from the contractor's point of view for the project $i$ up to the end of the period $j$

Models II and Model B.I aim to maximize the contractors' total satisfaction which cannot exceed their satisfaction in each period. It is guaranteed based on Objective Functions (5) and (B.1) and Constraints (6) and (B.2) in these models. Moreover, the total budgets allocated to the projects in each period cannot exceed the budget assigned to that period: it is guaranteed by Constraint (7) and (B.3) in these models. Finally, the sum of budgets paid for the project $i$ in all periods should be equal to the total cost needed for the project; it is guaranteed by Constraint (8) and (B.4) in these models.

Model II is used when the contractors determine their satisfying costs up to the end of each period cumulatively; the start dates of the projects are unchangeable. In Model B.I, the start date of the projects varies. Similar to Model A.I, this model needs to use the binary variable $y_{i}^{k}$ and Constraint (B.6). In other words, Constraint (B.6) in Model B.I guarantees that the project $i$ has only one start date. $M$ in this model is a large positive number.

\subsection{Budget allocation with the aim of maximizing both client's and contractors' satisfaction}

In budgets allocation, clients and contractors sometimes follow contradictory goals. In other words, 
Table 1. The information of projects portfolio of Khuzestan Steel Company.

\begin{tabular}{cccc}
\hline Project & Goal & Time (3 months) & Total budget (B rials) \\
\hline A & Development & 8 & 22 \\
B & Energy stabilization & 6 & 13 \\
C & Environmental protection & 5 & 2 \\
D & Renovation & 4 & 2.9 \\
E & Environmental protection & 4 & 1 \\
\hline
\end{tabular}

the client usually prefers allocating the majority of the budget in the final periods of the project's lifecycle, while contractors often prefer receiving most of the budget in the initial periods. In this section, optimization models are proposed to allocate the budget; they maximize the satisfaction of both the client and the contractors. In other words, these models represent a combination of the models presented in A and B. Two conditions are considered here and accordingly, different models are presented; the start date of projects can be fixed and unchangeable versus flexible and variable. If the start dates are fixed, Model III is used. However, if the start dates are flexible, Model C.I given in Appendix $\mathrm{C}$ is applied. In this case, all parameters and variables except $\lambda$ are those given in Models I, A.I, II and B.I. Here, $\lambda$ represents the final satisfaction of both client and contractors.

Model III,

$\max \lambda$,

s.t.:

$$
\begin{aligned}
& \lambda \leq \frac{A B_{j}^{U}-\sum_{i=1}^{n} \sum_{L=1}^{j} x_{i L}}{A B_{j}^{U}-A B_{j}^{L}} \quad \forall_{j}, \\
& \lambda \leq \frac{\sum_{h=1}^{j} x_{i h}-A C_{i j}^{L}}{A C_{i j}^{U}-A C_{i j}^{L}} \quad \forall_{i, j}, \\
& \sum_{j=1}^{t} x_{i j}=C_{i} \quad \forall_{i}, \\
& x_{i j} \geq 0 \quad \forall_{i, j},
\end{aligned}
$$

Models III and C.I aim to maximize both client and contractors' final satisfaction simultaneously which cannot exceed the client and contractors' satisfaction in each period. This is guaranteed based on Objective Function (10) and (C.1) and Constraints (11), (12), (C.2), and (C.3) in both models. Moreover, Constraints (13) and (C.4) in these models ensure that the total budgets for the projects are allocated. Finally, Constraints (C.6) show that every project has only one start date. Model III is used when the start dates of the projects are unchangeable. However, in Model B.I, the start dates of the projects may vary.

\section{Numerical illustration}

In order to illustrate the presented models, a real project portfolio of Khuzestan Steel Company consisting of five projects is used. These projects "A, B, C, $\mathrm{D}$, and $\mathrm{E}$ " require total costs, as shown in Table 1, and must be completed in specified successive periods. The company as the client may express its satisfaction with allocable budgets in different ways: fixed budget for each period or fuzzy cumulative budget up to the end of each period. These are illustrated by the data given in Tables 2 and 3 . The fuzzy specification for the fuzzy budgets given in Table 3 corresponding to "should be less than" and the membership function form is shown in Figure 1. Contractors may also express their satisfaction with the costs allocated to their projects in different ways: fixed cost for each period or fuzzy cumulative cost up to the end of each period. These are illustrated by contractors given in Tables 4 and 5 . The fuzzy specification for the fuzzy costs given in Table 5 corresponding to "should be more than" and the membership function form is shown in Figure 2.

Depending on the satisfaction expressed by the client and the contractors (Tables 3 to 5), six different examples were modeled and solved. It should be noted that in odd examples, the projects start in Period 1. In even examples, however, the start dates of the projects should not be necessarily the first period, although they all must finish up to eight periods. In other words, in these examples, project $B$ which requires six successive periods is allowed to start in periods 1,2 , or 3 . Project $\mathrm{C}$ that requires four successive periods can start in periods 1, 2, 3 or 4, etc. However, the project $\mathrm{A}$ that requires eight consecutive periods should start in period 1 in all examples. In these examples, it is also assumed that if a project starts with a delay, its costs do not vary.

The aim of Examples 1 and 2 is to maximize

Table 2. The fixed budget for each period.

\begin{tabular}{lllllllll} 
Period & 1 & 2 & 3 & 4 & 5 & 6 & 7 & 8 \\
Budget & 5 & 5 & 6 & 6 & 6 & 7 & 7 & 6 \\
\hline
\end{tabular}


Table 3. The fuzzy allocable cumulative budgets up to the end of each period.

\begin{tabular}{ccccccccc}
\hline Period & 1 & 2 & 3 & 4 & 5 & 6 & 7 & 8 \\
Satisfying budget & 4 & 8 & 12.5 & 18 & 23.5 & 30 & 37 & 40.9 \\
Unsatisfying budget & 6 & 11 & 18 & 25 & 33 & 38 & 42 & 47 \\
\hline
\end{tabular}

Table 4. The fixed costs needed for projects in each period.

\begin{tabular}{|c|c|c|c|c|c|c|c|c|}
\hline \multirow[b]{2}{*}{ Project } & \multicolumn{8}{|c|}{ Period } \\
\hline & 1 & 2 & 3 & 4 & 5 & 6 & 7 & 8 \\
\hline A & 2.4 & 2.5 & 2.7 & 2.9 & 2.9 & 2.6 & 2.5 & 2.3 \\
\hline B & 1.6 & 1.8 & 2.4 & 2.4 & 2.2 & 1.9 & 0 & 0 \\
\hline $\mathrm{C}$ & 0.3 & 0.35 & 0.45 & 0.35 & 0.3 & 0 & 0 & 0 \\
\hline $\mathrm{D}$ & 0.4 & 0.9 & 0.9 & 0.4 & 0 & 0 & 0 & 0 \\
\hline $\mathrm{E}$ & 0.1 & 0.3 & 0.3 & 0.1 & 0 & 0 & 0 & 0 \\
\hline
\end{tabular}

Table 5. The fuzzy cumulative cost for projects up to the end of each period.

\begin{tabular}{|c|c|c|c|c|c|c|c|c|c|}
\hline \multirow[t]{2}{*}{ Project } & & \multicolumn{8}{|c|}{ Period } \\
\hline & & 1 & 2 & 3 & 4 & 5 & 6 & 7 & 8 \\
\hline \multirow{2}{*}{ A } & Satisfying cost & 3.5 & 5.2 & 8.9 & 13.75 & 15.6 & 17.7 & 20.8 & 22 \\
\hline & Unsatisfying cost & 2.32 & 4.5 & 7.1 & 10 & 12.95 & 16 & 18 & 21 \\
\hline \multirow{2}{*}{ B } & Satisfying cost & 2.85 & 5.6 & 7.2 & 10.72 & 11.9 & 13 & 0 & 0 \\
\hline & Unsatisfying cost & 1.5 & 4.5 & 5.4 & 8.5 & 10.2 & 11.8 & 0 & 0 \\
\hline \multirow{2}{*}{$\mathrm{C}$} & Satisfying cost & 0.75 & 1.05 & 1.48 & 1.8 & 2 & 0 & 0 & 0 \\
\hline & Unsatisfying cost & 0.26 & 0.65 & 1.18 & 1.54 & 1.6 & 0 & 0 & 0 \\
\hline \multirow{2}{*}{$\mathrm{D}$} & Satisfying cost & 0.8 & 1.95 & 2.51 & 2.9 & 0 & 0 & 0 & 0 \\
\hline & Unsatisfying cost & 0.3 & 1.22 & 2.13 & 2.7 & 0 & 0 & 0 & 0 \\
\hline \multirow{2}{*}{$\mathrm{E}$} & Satisfying cost & 0.45 & 0.65 & 0.9 & 1 & 0 & 0 & 0 & 0 \\
\hline & Unsatisfying cost & 0.1 & 0.3 & 0.75 & 0.9 & 0 & 0 & 0 & 0 \\
\hline
\end{tabular}

the client's satisfaction under different conditions. The optimal solution to these examples is shown in Table 6 . However, Examples 3 and 4 aim to maximize the contractors' satisfaction; the optimal solution to these examples is given in Table 7. Finally, Examples 5 and 6 represent the attempt to maximize the satisfaction of both client and contractors (overall satisfaction) under different conditions; the optimal solution is given in Table 8.

\section{Example 1}

Assume that the client expresses the satisfaction with the allocable budget in the form of fuzzy budget cumulatively up to the end of each period, where the contractors express their satisfaction as the fixed cost in each period (Tables 3 and 4 ). In this case, Model I is used to maximize the client's satisfaction.

\section{Example 2}

In Example 1, if projects are allowed to start from each period, the client's maximum satisfaction can be obtained by solving Model B.I.

\section{Example 3}

The client may express satisfaction as the fixed budget for each period (Table 2), while contractors may express their satisfaction in a fuzzy manner up to the end of each period (Table 5). In this case, Model II is used to maximize contractors' satisfaction.

\section{Example 4}

Provided that the projects are flexible to start from each period in Example 3, contractors' maximum satisfaction is obtained using Model B.I. 
Table 6. Optimal budget allocation for Examples 1 and 2 to maximize the client's satisfaction.

\begin{tabular}{|c|c|c|c|c|c|c|c|c|c|c|}
\hline \multirow[b]{2}{*}{ Example } & \multirow{2}{*}{$\begin{array}{c}\text { The optimal } \\
\text { value of } \\
\text { the objective } \\
\text { function }\end{array}$} & \multirow[b]{2}{*}{ Project } & \multicolumn{8}{|c|}{ Period } \\
\hline & & & 1 & 2 & 3 & 4 & 5 & 6 & 7 & 8 \\
\hline \multirow{5}{*}{1} & \multirow{5}{*}{0.109} & A & 2.400 & 2.500 & 2.700 & 2.962 & 3.149 & 2.867 & 2.803 & 2.618 \\
\hline & & B & 1.600 & 1.800 & 2.400 & 2.465 & 2.499 & 2.236 & - & - \\
\hline & & $\mathrm{C}$ & 0.300 & 0.350 & 0.450 & 0.409 & 0.491 & - & - & - \\
\hline & & $\mathrm{D}$ & 0.400 & 0.900 & 0.900 & 0.700 & - & - & - & - \\
\hline & & $\mathrm{E}$ & 0.100 & 0.300 & 0.300 & 0.300 & - & - & - & - \\
\hline \multirow{5}{*}{2} & \multirow{5}{*}{0.556} & A & 2.600 & 2.700 & 2.900 & 3.000 & 3.000 & 2.800 & 2.700 & 2.300 \\
\hline & & B & - & 1.650 & 2.000 & 2.500 & 2.500 & 2.350 & 2.000 & - \\
\hline & & $\mathrm{C}$ & - & - & 0.350 & 0.400 & 0.500 & 0.400 & 0.350 & - \\
\hline & & $\mathrm{D}$ & - & - & 0.450 & 1.000 & 1.000 & 0.450 & - & - \\
\hline & & $\mathrm{E}$ & - & - & 0.150 & 0.350 & 0.350 & 0.150 & - & - \\
\hline
\end{tabular}

Table 7. Optimal budget allocation for Examples 3 and 4 to maximize the contractors' satisfaction.

\begin{tabular}{|c|c|c|c|c|c|c|c|c|c|c|}
\hline \multirow[b]{2}{*}{ Example } & \multirow{2}{*}{$\begin{array}{l}\text { The optimal } \\
\text { value of } \\
\text { the objective } \\
\text { function }\end{array}$} & \multirow[b]{2}{*}{ Project } & \multicolumn{8}{|c|}{ Period } \\
\hline & & & 1 & 2 & 3 & 4 & 5 & 6 & 7 & 8 \\
\hline \multirow{5}{*}{3} & \multirow{5}{*}{0.050} & A & 2.574 & 2.439 & 2.449 & 2.727 & 2.898 & 3.000 & 3.503 & 2.412 \\
\hline & & B & 1.725 & 1.796 & 2.606 & 2.485 & 1.820 & 2.568 & - & - \\
\hline & & $\mathrm{C}$ & 0.366 & 0.437 & 0.397 & 0.354 & 0.447 & - & - & - \\
\hline & & $\mathrm{D}$ & 0.947 & 0.868 & 0.578 & 0.507 & - & - & - & - \\
\hline & & $\mathrm{E}$ & 0.203 & 0.273 & 0.284 & 0.240 & - & - & - & - \\
\hline \multirow{5}{*}{4} & \multirow{5}{*}{1.074} & A & 2.293 & 1.502 & 3.283 & 2.709 & 2.470 & 2.215 & 2.594 & 4.934 \\
\hline & & B & - & 3.273 & 2.068 & 1.954 & 2.233 & 1.988 & 1.484 & - \\
\hline & & $\mathrm{C}$ & - & 0.591 & 0.514 & 0.301 & 0.296 & 0.298 & - & - \\
\hline & & $\mathrm{D}$ & - & - & - & 0.722 & 0.687 & 0.655 & 0.836 & - \\
\hline & & $\mathrm{E}$ & - & - & - & 0.249 & 0.249 & 0.280 & 0.222 & - \\
\hline
\end{tabular}

\section{Example 5}

Assume that both the client and the contractors express their satisfaction in a cumulative fuzzy up to the end of each period. In this case, the maximum total satisfaction is obtained by solving Model III.

\section{Example 6}

Provided that the projects are allowed to start from each period in Example 5, the total satisfaction is obtained by solving Model B.I.

\section{Discussion}

Project managers focus on solving resource-constrained project portfolio scheduling problems. Previous studies have emphasized the application of various PRs. This study focused on ensuring satisfaction with allocation of resources to the projects. Satisfaction is a binary relationship between resources and constraints [33], and it means that the resource is allocated in a way that the allocated resource is accepted by the distributor (the client) and the recipient (the contractors). The models presented in this paper focus on the budget distribution and consider the tolerance levels determined by the client and contractors so as to increase their satisfaction, and these models conform to the model proposed by Dubios and Fortemps [15] for solving the constraint satisfaction problems. The features and objectives of these models are summarized in Table 9 .

In the current research, three different categories 
Table 8. Optimal budget allocation for Examples 5 and 6 to maximize both the client's and contractors' satisfaction.

\begin{tabular}{|c|c|c|c|c|c|c|c|c|c|c|}
\hline \multirow[b]{2}{*}{ Example } & \multirow{2}{*}{$\begin{array}{c}\text { The optimal } \\
\text { value of } \\
\text { the objective } \\
\text { function }\end{array}$} & \multirow[b]{2}{*}{ Project } & \multicolumn{8}{|c|}{ Period } \\
\hline & & & 1 & 2 & 3 & 4 & 5 & 6 & 7 & 8 \\
\hline \multirow{5}{*}{5} & \multirow{5}{*}{0.042} & A & 2.454 & 2.183 & 2.772 & 3.250 & 2.809 & 2.609 & 3.513 & 2.410 \\
\hline & & B & 1.741 & 1.941 & 2.420 & 2.497 & 2.153 & 2.248 & - & - \\
\hline & & $\mathrm{C}$ & 0.399 & 0.418 & 0.383 & 0.352 & 0.448 & - & - & - \\
\hline & & $\mathrm{D}$ & 0.635 & 0.685 & 0.854 & 0.727 & - & - & - & - \\
\hline & & $\mathrm{E}$ & 0.309 & 0.049 & 0.518 & 0.124 & - & - & - & - \\
\hline \multirow{5}{*}{6} & \multirow{5}{*}{0.653} & A & 3.431 & 2.572 & 3.025 & 3.421 & 2.414 & 2.350 & 2.795 & 1.993 \\
\hline & & B & - & - & 2.382 & 2.434 & 2.492 & 2.642 & 1.502 & 1.548 \\
\hline & & $\mathrm{C}$ & - & - & 0.580 & 0.331 & 0.465 & 0.334 & 0.290 & - \\
\hline & & $\mathrm{D}$ & - & - & 0.849 & 0.848 & 0.697 & 0.507 & - & - \\
\hline & & $\mathrm{E}$ & - & - & 0.329 & 0.227 & 0.293 & 0.152 & - & - \\
\hline
\end{tabular}

Table 9. Features of Examples 1 to 6.

\begin{tabular}{|c|c|c|c|c|c|}
\hline Example & $\begin{array}{l}\text { Objective } \\
\text { function }\end{array}$ & $\begin{array}{l}\text { Presenting the } \\
\text { budget as }\end{array}$ & $\begin{array}{c}\text { Presenting } \\
\text { costs of } \\
\text { projects as }\end{array}$ & $\begin{array}{l}\text { All projects } \\
\text { obligated to } \\
\text { start in } \\
\text { period } 1 \\
\end{array}$ & $\begin{array}{l}\text { The proposed } \\
\text { model }\end{array}$ \\
\hline 1 & $\begin{array}{l}\text { Maximizing client's } \\
\text { satisfaction }\end{array}$ & $\begin{array}{c}\text { Cumulative fuzzy } \\
\text { value up to } \\
\text { the end of } \\
\text { each period }\end{array}$ & $\begin{array}{c}\text { Fixed value } \\
\text { in each } \\
\text { period }\end{array}$ & Yes & I \\
\hline 2 & $\begin{array}{l}\text { Maximizing client's } \\
\text { satisfaction }\end{array}$ & $\begin{array}{c}\text { Cumulative fuzzy } \\
\text { value up to } \\
\text { the end of } \\
\text { each period }\end{array}$ & $\begin{array}{c}\text { Fixed value } \\
\text { in each } \\
\text { period }\end{array}$ & $\begin{array}{c}\text { Not } \\
\text { necessary }\end{array}$ & A.I \\
\hline 3 & $\begin{array}{c}\text { Maximizing contractors' } \\
\text { satisfaction }\end{array}$ & $\begin{array}{c}\text { Fixed value } \\
\text { in each } \\
\text { period }\end{array}$ & $\begin{array}{c}\text { Cumulative fuzzy } \\
\text { value up to } \\
\text { the end of } \\
\text { each period }\end{array}$ & Yes & II \\
\hline 4 & $\begin{array}{c}\text { Maximizing contractors' } \\
\text { satisfaction }\end{array}$ & $\begin{array}{c}\text { Fixed value } \\
\text { in each } \\
\text { period }\end{array}$ & $\begin{array}{l}\text { Cumulative fuzzy } \\
\text { value up to } \\
\text { the end of } \\
\text { each period }\end{array}$ & $\begin{array}{c}\text { Not } \\
\text { necessary }\end{array}$ & B.I \\
\hline 5 & $\begin{array}{l}\text { Maximizing global } \\
\text { satisfaction }\end{array}$ & $\begin{array}{c}\text { Cumulative fuzzy } \\
\text { value up to } \\
\text { the end of } \\
\text { each period }\end{array}$ & $\begin{array}{c}\text { Cumulative fuzzy } \\
\text { value up to } \\
\text { the end of } \\
\text { each period }\end{array}$ & Yes & III \\
\hline 6 & $\begin{array}{l}\text { Maximizing global } \\
\text { satisfaction }\end{array}$ & $\begin{array}{c}\text { Cumulative fuzzy } \\
\text { value up to } \\
\text { the end of } \\
\text { each period }\end{array}$ & $\begin{array}{l}\text { Cumulative fuzzy } \\
\text { value up to } \\
\text { the end of } \\
\text { each period }\end{array}$ & $\begin{array}{c}\text { Not } \\
\text { necessary }\end{array}$ & C.I \\
\hline
\end{tabular}


of the allocation model in two different cases (start date of project is constant or flexible) have been presented. In the first category, the client's satisfaction has been measured and the contractors' viewpoints have not been considered. On the contrary, only the contractors' satisfaction has been calculated in the second category, while the client's satisfaction has not been studied. These categories can be used depending on what strategy is followed by the portfolio manager. However, if the manager seeks to consider the client and contractors' points of view simultaneously, the third category is proposed. These models are applied independently so that the manager's strategies define which one to use.

According to the results, models with flexibility at the start dates result in achieving greater satisfaction than those with the constant start dates. For example, in Example 1 in which projects must start from the first period, the client's satisfaction is 0.109 , while it increases to 0.556 by making the start dates flexible in Example 2. In Example 2, the project B starts in period 2 and other projects start in period 3, thus allowing the client to offset the budget deficit in the first period in subsequent periods. In case the budget is presented cumulatively, budget deficit in each period can be compensated in subsequent cumulative payments.

The models presented in this research can be compared with the two-stage methods proposed by Kurtulus and Davis [31] and Lova and Tormos [32] in which the portfolio manager defines restrictions for each project according to resource constraint in the first stage. Then, the project managers, according to their priorities, use the results of the proposed model as a constraint and carry out their project scheduling independently. In other words, the results of the model presented in this paper can be input data for RCPSP models such as those presented by Kaveh and Vazirinia [34], Tavaana et al. [35], and Paraskevopoulos et al. [36].

The results of the real case show that the models avoid delays that result from resource deficit by providing sustainable budget during the model implementation. This finding is consistent with that of the study achieved by Chakrabortty et al. [22] who stated that choosing an appropriate method could affect the sustainability of the project time. In this respect, Herroelen [26] emphasized that the primary purpose of an RCMPS solution was to stabilize scheduling.

Adhau et al. [11] pointed to the practical problems and lack of information exchange. These problems were solved by the models presented in this paper because the client's and the contractors' viewpoints were considered simultaneously. Wang et al. [37], Wanke et al. [38], and Mirzaei et al. [39] pointed to data uncertainty; this study attempted to consider ambiguity in data as fuzzy concepts in the proposed models.

\section{Conclusions and future research}

The models proposed in this research offer an approach to solving Resouce-Constrained Multi-Project Scheduling Problem (RCMPSP) by maximizing the client's and the contractors' satisfaction. Three distinct goals were considered in this research: maximizing the client's satisfaction, maximizing contractors' satisfaction, and maximizing the client's and contractors' satisfaction simultaneously. In each case, cumulative payments were assumed. Moreover, two ways were considered for each payment assumption: flexibility on the start dates of the projects and initiation of all the projects in the first period. The results of the real case projects portfolio achieved by the proposed models demonstrated that the proposed approach had a significant ability to allocate budget appropriately. Due to the simultaneous participation of the two main projects partners, i.e., the client and the contractors, the present models are more likely to be applicable. Because input information was provided by the stakeholders, their commitment to complying with the limits on the implementation phase increased. Moreover, the application of the models presented in this research led to a reduction in many project managers' objections and lobbies in funding. Also, the improvement of the satisfaction level would increase the focus on lower-level scheduling.

Although the proposed models in the current research reveal appropriate abilities, they are subject to constraints in terms of their application. First, data gathering in the case of these models needs a considerable collaboration between project managers and contractors. This issue requires proper coordination and time. Second, the models are solved through mathematical schemes. The corresponding computation can be complicated for large-scale multi-projects and high-performance computers are required. Finally, the satisfaction with the budget directly corresponds to the experience of the client and contractors. This is the reason why the performance of the models has been influenced by users.

One method cannot indeed be used to solve all RCMPSP problems; however, having a variety of methods in different situations improves the scheduling outcomes. Therefore, it is suggested for future research that the proposed approach be combined with other PRs. In the present model, the weight of all projects was considered equal in terms of importance; thus, it is suggested that projects with different weights and importance be considered in the model. On the other hand, in the model assumptions, the implementation and payment periods were considered sequential and consecutive; in practice, however, delays may occur 
during the execution of the projects. To make improvements, the possibility of delays occurring in projects or changes in scheduling can also be examined. Furthermore, in this research, the payment was assumed to be cumulative which could be applied in some projects individually. It is suggested that these models be examined through different payments.

\section{Acknowledgements}

The authors are grateful for the constructive comments and suggestions made by the anonymous referees and the Editor-in-Chief, Professor Niaki.

\section{References}

1. Lim, C., Teng, S.G., Al-Ghandour, M., et al. "Let scheduling for funding scenario analysis of highway construction projects with a case of NCDOT", IEEE Transactions on Engineering Management, 67(2), pp. 385-395 (2018)

2. Elazouni, A.M. and Metwally, F.G. "Finance-based scheduling: Tool to maximize project profit using improved genetic algorithms", Journal of Construction Engineering and Management, 131(4), pp. 400-412 (2005).

3. Afshar, A. and Fathi, H. "Fuzzy multi-objective optimization of finance-based scheduling for construction projects with uncertainties in cost", Engineering Optimization, 41(11), pp. 1063-1080 (2009).

4. Wang, Y., He, Z., Kerkhove, L., et al. "On the performance of priority rules for the stochastic resource constrained multi-project scheduling problem", Computers \& Industrial Engineering, 114, pp. 223-234 (2017).

5. Browning, T. and Yassine, A. "Resource-constrained multi-project scheduling: Priority rule performance revisited", International Journal of Production Economics, 126(2), pp. 212-228 (2010).

6. Yang, K.K. and Sum, C.C. "A comparison of resource allocation and activity scheduling rules in a dynamic multi-project environment", Journal of Operations Management, 11(2), pp. 207-218 (1993).

7. Gonçalves, J., Mendes, J., and Resende, M. "A genetic algorithm for the resource constrained multi-project scheduling problem", European Journal of Operational Research, 189(3), pp. 1171-1190 (2008).

8. Ju, C. and Chen, T. "Simplifying multiproject scheduling problem based on design structure matrix and its solution by an improved aiNet algorithm", Discrete Dynamics in Nature and Society, 2012, Article ID 713740, p. 22 (2012).

9. Hartmann, S. and Kolisch, R. "Experimental evaluation of state-of-the-art heuristics for the resourceconstrained project scheduling problem", European Journal of Operational Research, 127(2), pp. 394-407 (2000).
10. Browning, T.R. and Yassine, A.A. "Managing a portfolio of product development projects under resource constraints", Decision Sciences, 47(2), pp. 333-372 (2016).

11. Adhau, S., Mittal, M., and Mittal, A. "A multiagent system for distributed multi-project scheduling: An auction-based negotiation approach", Engineering Applications of Artificial Intelligence, 25(8), pp. 17381751 (2012).

12. Lau, J., Huang, G.Q., Mak, K.L., et al. "Distributed project scheduling with information sharing in supply chains: part I-an agent-based negotiation model", International Journal of Production Research, 43(22), pp. $4813-4838$ (2005).

13. Akhbari, M. "Partnership of contractors in cooperative game theory approach to project resource management", Scientia Iranica, 27(1), pp. 469-480 (2020).

14. Singh, A. "Resource constrained multi-project scheduling with priority rules \& analytic hierarchy process", Procedia Engineering, 69, pp. 725-734 (2014).

15. Dubois, D. and Fortemps, P. "Computing improved optimal solutions to max-min flexible constraint satisfaction problems", European Journal of Operational Research, 118(1), pp. 95-126 (1999).

16. Zimmermann, H.J. "Description and optimization of fuzzy systems", International Journal of General System, 2(1), pp. 209-215 (1975).

17. Pritsker, A., Waiters, L., and Wolfe, P. "Multi project scheduling with limited resources: A zero-one programming approach", Management Science, 16(1), pp. 93-108 (1969).

18. Kim, K., Yun, Y., Yoon, J., et al. "Hybrid genetic algorithm with adaptive abilities for resource-constrained multiple project scheduling", Computers in Industry, 56(2), pp. 143-160 (2005).

19. Tseng, C.C. "Two heuristic algorithms for a multimode resource-constrained multi-project scheduling problem", Journal of Science and Engineering Technology, 4(2), pp. 63-74 (2008).

20. Majazi Dalfard, V. and Ranjbar, V. "Multi-projects scheduling with resource constraints \& priority rules by the use of simulated annealing Algorithm", Tehnicki Vjesnik, 19(3), pp. 493-499 (2012).

21. Can, A. and Ulusoy, G. "Multi-project scheduling with two-stage decomposition", Annals of Operations Research, 217(1), pp. 95-116 (2014).

22. Chakrabortty, R.K., Sarker, R.A., and Essam, D.L., Resource Constrained Multi-project Scheduling: A Priority Rule Based Evolutionary Local Search Approach in Intelligent and Evolutionary Systems, pp. 75-86, Springer, Cham (2017).

23. Kurtulus, I.S. and Narula, S.C. "Multi-project scheduling: Analysis of project performance", IIE Transactions, 17(1), pp. 58-66 (1985).

24. Russell, R.A. "A comparison of heuristics for scheduling projects with cash flows and resource restrictions", Management Science, 32(10), pp. 1291-1300 (1986). 
25. Chiu, H.N. and Tsai, D.M. "An efficient search procedure for the resource-constrained multi-project scheduling problem with discounted cash flows", Construction Management \& Economics, 20(1), pp. 55-66 (2002).

26. Herroelen, W. "Project scheduling-theory and practice", Production and Operations Management, 14(4), pp. 413-432 (2005).

27. Vázquez, E.P., Calvo, M.P., and Ordónez, P.M. "Learning process on priority rules to solve the RCMPSP", Journal of Intelligent Manufacturing, 26(1), pp. 123-138 (2015).

28. Ben Issa, S. and Yiliu, Tu. "A survey in the resourceconstrained project and multi-project scheduling problems", Journal of Project Management, 5, pp. 117-138 (2020).

29. Nabipoor Afruzi, E., Aghaie, A., and Najafi, A.A. "Robust optimization for the resource-constrained multiproject scheduling problem with uncertain activity durations", Scientia Iranica, 27(1), pp. 361-376 (2020).

30. Zhang, Z., Xu, J., Yang, H., et al. "Bi-elvel optimization of resource-constrained multiple project scheduling problems in hydropower station construction under uncertainty", Scientia Iranica, 22(3), pp. 650-667 (2015).

31. Kurtulus, I. and Davis, E.W. "Multi-project scheduling: Categorization of heuristic rules performance", Management Science, 28(2), pp. 161-172 (1982).

32. Lova, A. and Tormos, P. "Analysis of scheduling schemes and heuristic rules performance in resourceconstrained multiproject scheduling", Annals of Operations Research, 102(1-4), pp. 263-286 (2001).

33. Tsang, E., Foundations of Constraint Satisfaction: The Classic Text, pp. 8-10, BoD-Books on Demand (2014).

34. Kaveh, A. and Vazirinia, Y. "Chaotic vibrating particles system for resource-constrained project scheduling problem", Scientia Iranica, 27(4), pp. 1826-1842 (2020).

35. Tavana, M., Abtahi, A.R., and Khalili-Damghani, K. "A new multi-objective multi-mode model for solving preemptive time-cost-quality trade-off project scheduling problems", Expert Systems with Applications, 41(4), pp. 1830-1846 (2014).

36. Paraskevopoulos, D.C., Tarantilis, C.D., and Ioannou, G. "Solving project scheduling problems with resource constraints via an event list-based evolutionary algorithm", Expert Systems with Applications, 39(4), pp. 3983-3994 (2012).

37. Wang, X., Chen, Q., Mao, N., et al. "Proactive approach for stochastic RCMPSP based on multipriority rule combinations", International Journal of Production Research, 53(4), pp. 1098-1110 (2014).

38. Wanke, P., Nwaogbe, O.R., and Chen, Z. "Efficiency in Nigerian ports: handling imprecise data with a twostage fuzzy approach", Maritime Policy \& Management, 45(5), pp. 699-715 (2018).
39. Mirzaei, N., Niroomand, S., and Zare, R. "Application of statistical process control in service industry: A case study of the restaurant sector", Journal of Modelling in Management, 11(3), pp. 763-782 (2016).

\section{Appendix A}

The model used for maximizing the client's satisfaction when the start dates of projects are flexible:

Model A.I

$\max \lambda$

$$
\begin{aligned}
& \lambda \leq \frac{A B_{j}^{U}-\sum_{i=1}^{n} \sum_{L=1}^{j} \sum_{k=1}^{j} x_{i L}^{k}}{A B_{j}^{U}-A B_{j}^{L}} \forall_{j}, \\
& \sum_{j=k}^{k+n_{i}-1} x_{i j}^{k}-C_{i}^{k} \times y_{i}^{k}=0 \quad \forall_{i}, \\
& x_{i j}^{k}-C_{i j}^{k} \times y_{i}^{k}=0 \quad \forall_{i, j, k}, \\
& \sum_{k} y_{i}^{k}=1 \quad \forall_{i}, \\
& x_{i j}^{k} \geq 0 \quad \forall_{i, j}, \\
& y_{i}^{k}=0,1 \quad \forall_{i, k},
\end{aligned}
$$

where:

$x_{i L}^{k} \quad$ The budget paid for the project $i$ in the period $j$ provided that the project starts in the period $k$

$y_{i}^{k} \begin{cases}0 & \text { if project } i \text { does not start in period } k \\ 1 & \text { if project } i \text { starts in period } k\end{cases}$

$C_{i j}^{k} \quad$ The cost required for the project $i$ in the period $j$ provided that the project starts in the period $k$

$C_{i}^{k} \quad$ Total cost of the project $i$ provided that the project starts in the period $k$

\section{Appendix B}

The model used for maximizing the contractors' satisfaction when the start dates of projects are flexible:

Model B.I

$\max \lambda$,

s.t.:

$$
\begin{gathered}
-\sum_{h=k}^{j} x_{i h}^{k}+\left(A C_{i j}^{k U}-A C_{i j}^{k L}\right) \times \lambda \leq M\left(1-y_{i}^{k}\right) \\
-A C_{i j}^{k L} \quad \forall_{i, j, k}, \\
\sum_{i=1}^{n} \sum_{k=1}^{j} x_{i j}^{k} \leq B_{j} \quad \forall_{j},
\end{gathered}
$$




$$
\begin{aligned}
& \sum_{i=k}^{k+n_{i}-1} x_{i j}^{k}-C_{i}^{k} \times y_{i}^{k}=0 \quad \forall_{i, k}, \\
& x_{i j}^{k} \geq 0 \quad \forall_{i, j} \\
& \sum_{k} y_{i}^{k}=1 \quad \forall_{i}, \\
& y_{i}^{k}=0,1 \quad \forall_{i, k},
\end{aligned}
$$

where:

$A C_{i j}^{k L} \quad$ The cumulative satisfying cost for the project $i$ up to the end of the period $j$ provided that the project starts in the period $k$

$A C_{i j}^{k U} \quad$ The maximum unsatisfying budget for the project $i$ up to the end of the period $j$ provided that the project starts in the period $k$

\section{Appendix C}

The model used for maximizing the client and contractors' satisfaction when the start dates of projects are flexible:

Model C.I

$\max \lambda$,

s.t.:

$$
\begin{aligned}
& \lambda \leq \frac{A B_{j}^{U}-\sum_{i=1}^{n} \sum_{L=1}^{j} \sum_{k=1, k \leq L}^{j} x_{i L}^{k}}{A B_{j}^{U}-A B_{j}^{L}} \forall_{j}, \\
& -\sum_{h=k}^{j} x_{i j}^{k}+\left[A C_{i j}^{k U}-A C_{i j}^{k L}\right] \times \lambda \leq M\left(1-y_{i}^{k}\right) \\
& \quad-A C_{i j}^{k L} \quad \forall_{i, j, k} \\
& \sum_{j=k}^{k+n_{i}-1} x_{i j}^{k}-C_{i}^{k} \times y_{i}^{k}=0 \quad \forall_{i}, \\
& x_{i j}^{k} \geq 0 \quad \forall_{i, j},
\end{aligned}
$$

$$
\begin{aligned}
& \sum_{k} y_{i}^{k}=1 \quad \forall_{i}, \\
& y_{i}^{k}=0,1 \quad \forall_{i, k} .
\end{aligned}
$$

\section{Biographies}

Farhad Khazaeli received his BSc degree from Islamic Azad University Ahvaz Branch in Civil Engineering and MS degree from Islamic Azad University Science and Research branch in Engineering and Construction Management. $\mathrm{He}$ is currently active in the same field in $\mathrm{PhD}$ course. His research interests include project management, budget allocation, meta-heuristic optimization methods, and multicriteria decision-making.

Hosein Arman is an Assistant Professor of Operations and Production Management at Islamic Azad University (IAU), Najafabad Branch, Iran. His research interests lie in the area of supply chain management, project control, budget allocation, data envelopment analysis, and fuzzy multi-criteria decisionmaking.

Mohammadreza Zare is an Assistant Professor of Engineering and Construction Management at University of Isfahan. He has been involved in the design, construction, evaluation, and renovation of infrastructure projects for more than two decades. His focus is on adopting new technologies for underground infrastructure development and renovation.

Abdollah Hadi-Vencheh is a Full Professor of Operations Research and Decision Sciences. His research interests lie in a broad area of performance management, data envelopment analysis, multi-criteria decisionmaking, fuzzy logic, and fuzzy decision-making. He has published systematically on these subjects in international peer-reviewed journals. 